\title{
PENINGKATAN BUDAYA KESELAMATAN PASIEN DALAM LINGKUP KEPERAWATAN
}

\author{
Fransiska Finishia Putri Zalukhu \\ vinisiazal12@gmail.com
}

\section{LATAR BELAKANG}

Rumah sakit sebagai sarana pelayanan kesehatan pada dasarnya adalah untuk menyelamatkan pasien, keselamatan pasien merupakan prioritas bagi pelaksanaan lima isu penting tentang keselamatan di rumah sakit, karena masalah keselamatan pasien berkaitan erat dengan kualitas dan citra rumah sakit itu sendiri. Perkembangan ilmu pengetahuan dan tekhnologi yang sedemikian pesat menyebabkan pelayanan kesehatan di rumah sakit menjadi sangat kompleks sehingga jika tidak dilakukan dengan benar dan hati-hati akan berpotensi untuk terjadinya Insiden Keselamatan Pasien (IKP) yang terdiri dari Kejadian Tidak Diharapkan (KTD), Kejadian Nyaris Cedera (KNC), Kejadian Tidak Cedera (KTC) dan Kondisi Potensial Cedera (KPC) (Depkes,2006).

Budaya Keselamatan pasien merupakan hal yang mendasar di dalam pelaksanaan keselamatan di rumah sakit. Rumah sakit harus menjamin penerapan keselamatan pasien pada pelayanan kesehatan yang diberikannya kepada pasien (Fleming \& Wentzel, 2008). Upaya dalam pelaksanaan keselamatan pasien diawali dengan penerapan budaya keselamatan pasien (KKP-RS, 2008). Hal tersebut dikarenakan berfokus pada budaya keselamatan akan menghasilkan penerapan keselamatan pasien yang lebih baik dibandingkan hanya berfokus pada program keselamatan pasien saja (El-Jardali, Dimassi, Jamal, Jaafar, \& Hemadeh, 2011). Budaya keselamatan pasien merupakan pondasi dalam usaha penerapan keselamatan pasien yang merupakan prioritas utama dalam pemberian layanan kesehatan (Disch, Dreher, Davidson, Sinioris, \& Wainio, 2011; NPSA, 2009). Pondasi keselamatan pasien yang baik akan meningkatkan mutu pelayanan kesehatan khususnya asuhan keperawatan.

Perawat adalah pejabat eksekutif kesehatan dengan waktu kerja tertinggi yang memberikan 24 jam pelayanan terus menerus serta harus berkolaborasi dengan tim kesehatan lain dan oleh karena itu lahhal tersebut dapat menyebabkan atau berisiko terjadinya Insiden Keselamatan Pasien1. Selain itu, perawat memiliki peran yang paling dominan dalam mencegah terjadinya kesalahan dalam pengobatan, termasuk pelaporan insiden, mendidik diri sendiri dan orang lain. Sejalan dengan definisi keperawatan ANA 2003 yang menyatakan bahwa keperawatan adalah perlindungan, promosi, dan optimalisasi kesehatan dan kemampuan, pencegahan penyakit dan cedera, pengentasan penderitaan melalui diagnosis dan pengobatan respon manusia, dan advokasi dalam perawatan individu, keluarga, masyarakat, dan populasi. 
Perawatan yang tidak aman yang dilakukan oleh petugas kesehatan di rumah sakit menjadi prioritas masalah yang harus segera diselesaikan. $83 \%$ kejadian yang menyebabkan pasien tidak aman merupakan kejadian yang seharusnya bisa dicegah dan 30\% diantaranya berkaitan dengan kematian pasien adanya tindakan yang tidak aman dikarenakan beberapa faktor diantaranya kurangnya pelatihan pengawasan, kegagalan menindaklanjuti kebijakan. Budaya keselamatan yang baik dapat mengurangi risiko terjadinya kejadian yang tidak diinginkan maka diperlukan pelatihan secara rutin bagi petugas medis agar benar-benar nnernahami budaya keselamatan pasien.' Pengawasan dari atasan juga harus ditingkatkan sebagai salah satu upaya untuk menerapkan budaya keselamatan pasien. Semua itu harus didukung dengan kebijakan dari atasan dan semua Petugas medis harus bisa menindaklanjuti setiap kebijakan yang dibuat.

\section{METODE}

Untuk mengetahui bagaimana dasar pelaksanaan dokumentasi dalam keperawatan maka dilakukan penelusuran literatur berupa buku, jurnal, artikel, jurnal online dan sebagainya kecuali blog pribadi. Literatur yang berfokus tentang budaya keselamatan pasien selama berada di rumah sakit, di mana ini budaya keselamatan pasien juga menjadi tolak ukur bagi pasien dan keluarga untuk menilai kinerja rumah sakit terutama dalam pelayanan kesehatan yang diberikan oleh petugas kesehatan terutama oleh perawat.

\section{HASIL}

Keselamatan pasien adalah prinsip dasar dalam pelayanan kesehatan. Menurut Depkes RI (2008) Keselamatan pasien (patient safety) rumah sakit adalah suatu sistem dimana rumah sakit membuat asuhan pasien lebih aman. Sistem tersebut meliputi: assessmen risiko, identifikasi dan pengelolaan hal yang berhubungan dengan risiko pasien, pelaporan dan analisis insiden, kemampuan belajar dari insiden dan tindaklanjutnya serta implementasi solusi untuk meminimalkan timbulnya risiko. Sistem tersebut diharapkan dapat mencegah terjadinya cedera yang disebabkan oleh kesalahan akibat melaksanakan suatu tindakan atau tidak melakukan tindakan yang seharusnya dilakukan. Salah satu tujuan keselamatan pasien yaitu menurunnya KTD yang merupakan bagian dari insiden keselamatan pasien. Untuk mencapai tujuan tersebut, maka disusunlah Sasaran

Keselamatan pasien yang bertujuan mendorong perbaikan spesifik dalam keselamatan pasien. Sasaran menyoroti bagian-bagian yang bermasalah dalam pelayanan kesehatan dan menjelaskan bukti serta solusi dari konsensus berbasis bukti dan keahlian atas permasalahan yang ada. Penyusunan sasaran ini mengacu kepada Nine Life-Saving Patient Safety Solutions dari WHO Patient Safety (2007) yang digunakan juga oleh Komite Keselamatan Pasien Rumah Sakit PERSI 
(KKPRS PERSI), dan dari Joint Commission International (JCI). Oleh karena itu, jika rumah sakit ingin menurunkan kejadian insiden keselamatan pasien maka rumah sakit harus menerapkan budaya keselamatan pasien. Sampai saat ini, banyak negara telah memulai penelitian budaya keselamatan pasien, baik Negara maju maupun Negara berkembang seperti Indonesia. Penelitian tentang budaya keselamatan pasien telah berkembang dalam beberapa tahun terakhir. Namun, masih kurang evaluasi objektif dan kuantitatif dari kualitas penelitian-penelitian tersebut. Tujuan dari tulisan ini adalah untuk mengetahui penerapan budaya keselamatan pasien terkait dengan insiden keselamatan pasien dengan berbasis bukti (Evidence Based).

Keselamatan (safety) telah menjadi isu global termasuk juga untuk rumah sakit. Oleh karena itu, keselamatan pasien merupakan prioritas utama untuk dilaksanakan dan hal tersebut terkait dengan terjadinya Insiden Keselamatan Pasien (IKP) di rumah sakit. Penerapan budaya keselamatan pasien yang adekuat akan menghasilkan pelayanan keperawatan yang bermutu. Pelayanan kesehatan yang bermutu tidak cukup dinilai dari kelengkapan teknologi, sarana prasarana yang canggih dan petugas kesehatan yang profesional, namun juga ditinjau dari proses dan hasil pelayanan yang diberikan (Ilyas, 2004). Outcome yang baik dapat tercapai jika terjadi peningkatan budaya keselamatan pasien di lingkungan rumah sakit. Peningkatan tersebut harus dipantau dan dapat diukur.

\section{PEMBAHASAN}

Menurut Vincent (2008), keselamatan pasien didefinisikan sebagai penghindaran, pencegahan dan perbaikan dari hasil tindakan yang buruk atau injuri yang berasal dari proses perawatan kesehatan. Definisi ini membawa beberapa cara untuk membedakan keselamatan pasien dari kekhawatiran yang lebih umum mengenai kualitas layanan kesehatan, yang disebut oleh Vincent sebagai "sisi gelap kualitas". Perawatan kesehatan, dalam banyak kasus setidaknya, sangat berbahaya dan definisi secara implisit mengakui hal ini. Definisi ini juga mengacu pada perbaikan hasil buruk atau injuri, yang memperluas definisi di luar masalah keselamatan tradisional terhadap area yang mungkin, di banyak industri, disebut manajemen bencana. Dalam perawatan kesehatan, perbaikan pertama-tama mengacu pada kebutuhan akan intervensi medis yang cepat untuk mengatasi krisis segera, tetapi juga untuk kebutuhan merawat pasien dengan injuri dan untuk mendukung staf yang terlibat. Keselamatan pasien terkait dengan "kualitas perawatan", namun kedua konsep tersebut tidak identik. Keselamatan merupakan bagian penting dari kualitas. Sampai saat ini, kegiatan untuk mengelola kualitas tidak terfokus secukupnya pada masalah keselamatan pasien (National Patient Safety Foundation, 2000, dalam Vincent, 2010). 
Kualitas perawatan telah menjadi fokus yang sangat penting di bidang perawatan kesehatan primer untuk beberapa waktu dan pekerjaan ini terkait dengan perbaikan hasil yang cukup besar pada pasien. Dalam bidang ini, pemeriksaan keselamatan pasien baru saja muncul sebagai fokus yang berbeda selama dekade terakhir. Ada kesadaran yang meningkat bahwa risiko yang teridentifikasi di sektor perawatan akut terwujud dalam berbagai cara dalam perawatan kesehatan primer. Solusi yang dikembangkan dalam perawatan akut belum tentu berlaku di sini. Praktisi perawatan kesehatan primer dapat belajar dari sektor perawatan akut, namun juga perlu memeriksa secara seksama proses dan sistem mereka sendiri untuk mengidentifikasi risiko pasien tertentu dan solusi yang mungkin terjadi.

Standar keselamatan pasien menurut PerMenKes Nomor 1691/Menkes/Per/VIII/2011 tentang Keselamatan Pasien Di Rumah Sakit pasal 7 ayat (2) meliputi:

1. Hak pasien.

2. Mendidik pasien dan keluarga.

3. Keselamatan pasien dan kesinambungan pelayanan.

4. Penggunaan metoda-metoda peningkatan kinerja untuk melakukan evaluasi dan program peningkatan keselamatan pasien

5. Peran kepemimpinan dalam meningkatkan keselamatan pasien

6. Mendidik staf tentang keselamatan pasien

7. Komunikasi merupakan kunci bagi staf untuk mencapai keselamatan pasien

Tujuan SKP adalah untuk menggiatkan perbaikan-perbaikan tertentu dalam soal keselamatan pasien. Sasaran sasaran dalam SKP menyoroti bidang-bidang yang bermasalah dalam perawatan kesehatan, memberikan bukti dan solusi hasil konsensus yang berdasarkan nasihat para pakar. Dengan mempertimbangkan bahwa untuk menyediakan perawatan kesehatan yang aman dan berkualitas tinggi diperlukan desain sistem yang baik, sasaran biasanya sedapat mungkin berfokus pada solusi yang berlaku untuk keseluruhan sistem. Di Indonesia secara nasional untuk seluruh Fasilitas pelayanan Kesehatan, diberlakukan Sasaran Keselamatan Pasien Nasional yang terdiri dari

SKP.1 Mengidentifikasi Pasien Dengan Benar

SKP.2 Meningkatkan Komunikasi Yang Efektif

SKP.3 Meningkatkan Keamanan Obat-obatan Yang Harus Diwaspadai

SKP.4 Memastikan Lokasi Pembedahan Yang Benar, Prosedur Yang Benar, Pembedahan Pada PasienYang Benar

SKP.5 Mengurangi Risiko Infeksi Akibat Perawatan Kesehatan 
SKP.6 Mengurangi Risiko Cedera Pasien Akibat Terjatuh

Acuan ini di antaranya mewujudkan tujuan keselamatan pasien dan menjamin berlangsungnya program proaktif untuk identifikasi risiko keselamatan pasien dan program menekan atau mengurangi insiden. Upaya-upaya tersebut bertujuan mendorong penerapan budaya keselamatan pasien di rumah sakit. Selain itu, budaya keselamatan pasien dibangun dengan diubahnya blaming culture menjadi safety culture. Membangun kesadaran akan nilai keselamatan pasien, memimpin dan mendukung staf dalam penerapan keselamatan pasien merupakan bagian penting dalam menciptakan budaya keselamatan pasien (Permenkes No. 1691, 2011). Salah satu strategi untuk mengembangkan budaya keselamatan adalah dengan melibatkan staf dalam perencanaan dan pengembangan budaya keselamatan pasien (Fleming, 2005). Pemberian tanggung jawab yang berorientasi pada keselamatan pasien dapat menciptakan budaya keselamatan yang diharapkan.

Perawat merupakan sumber daya manusia yang terpenting di rumah sakit. Hal ini dikarenakan perawat merupakan profesi yang memberikan pelayanan secara konstan dan berlangsung selama terusmenerus terhadap pasien setiap harinya. Dalam menjalankan tugasnya, seorang perawat pelaksana harus merencanakan waktunya sebaik mungkin.mdi sisi lain menyebutkan bahwa seorang perawat pelaksana merupakan tenaga kesehatan yang berdiri di barisan paling depan dalam menjamin keselamatan pasien, terutama pada pasien rawat inap. Hal ini dikarenakan perawat pelaksana memiliki kuantitas kontak langsung yang paling banyak dengan pasien dibandingkan dengan tenaga kesehatan lainnya. Jadi, hal ini bisa menjadikan sebuah keuntungan, dikarenakan pengalam perawat pelaksana dapat meningkatkan kualitas perawat dalam memberikan keselamatan bagi pasien di rumah sakit.

WHO Collaborating Centre for Patient safety pada tanggal 2 Mei 2007 resmi menerbitkan "Nine Life Saving Patient safety Solutions" ("Sembilan Solusi Life-Saving Keselamatan Pasien Rumah Sakit"). Panduan ini mulai disusun sejak tahun 2005 oleh pakar keselamatan pasien dan lebih 100 negara, dengan mengidentifikasi dan mempelajari berbagai masalah keselamatan pasien. Sebenarnya petugas kesehatan tidak bermaksud menyebabkan cedera pasien, tetapi fakta tampak bahwa di bumi ini setiap hari ada pasien yang mengalami KTD (Kejadian Tidak Diharapkan). KTD, baik yang tidak dapat dicegah (non error) mau pun yang dapat dicegah (error), berasal dari berbagai proses asuhan pasien. Solusi keselamatan pasien adalah sistem atau intervensi yang dibuat, mampu mencegah atau mengurangi cedera pasien yang berasal dari proses pelayanan kesehatan. Sembilan Solusi ini merupakan panduan yang sangat bermanfaat membantu RS, memperbaiki proses asuhan pasien, guna menghindari cedera maupun kematian yang dapat dicegah. Komite Keselamatan Pasien Rumah Sakit (KKPRS) mendorong RS-RS di Indonesia untuk menerapkan 
Sembilan Solusi Life-Saving Keselamatan Pasien Rumah Sakit, atau 9 Solusi, langsung atau bertahap, sesuai dengan kemampuan dan kondisi RS masing-masing.

a. Perhatikan Nama Obat, Rupa dan Ucapan Mirip (Look-Alike, Sound-Alike Medication Names).

Nama Obat Rupa dan Ucapan Mirip (NORUM), yang membingungkan staf pelaksana adalah salah satu penyebab yang paling sering dalam kesalahan obat (medication error) dan ini merupakan suatu keprihatinan di seluruh dunia. Dengan puluhan ribu obat yang ada saat ini di pasar, maka sangat signifikan potensi terjadinya kesalahan akibat bingung terhadap nama merek atau generik serta kemasan. Solusi NORUM ditekankan pada penggunaan protokol untuk pengurangan risiko dan memastikan terbacanya resep, label, atau penggunaan perintah yang dicetak lebih dulu, maupun pembuatan resep secara elektronik.

b. Pastikan Identifikasi Pasien.

Kegagalan yang meluas dan terus menerus untuk mengidentifikasi pasien secara benar sering mengarah kepada kesalahan pengobatan, transfusi maupun pemeriksaan; pelaksanaan prosedur yang keliru orang; penyerahan bayi kepada bukan keluarganya, dsb. Rekomendasi ditekankan pada metode untuk verifikasi terhadap identitas pasien, termasuk keterlibatan pasien dalam proses ini; standardisasi dalam metode identifikasi di semua rumah sakit dalam suatu sistem layanan kesehatan; dan partisipasi pasien dalam konfirmasi ini; serta penggunaan protokol untuk membedakan identifikasi pasien dengan nama yang sama.

c. Komunikasi Secara Benar saat Serah Terima/Pengoperan Pasien.

Kesenjangan dalam komunikasi saat serah terima/ pengoperan pasien antara unit-unit pelayanan, dan didalam serta antar tim pelayanan, bisa mengakibatkan terputusnya kesinambungan layanan, pengobatan yang tidak tepat, dan potensial dapat mengakibatkan cedera terhadap pasien. Rekomendasi ditujukan untuk memperbaiki pola serah terima pasien termasuk penggunaan protokol untuk mengkomunikasikan informasi yang bersifat kritis; memberikan kesempatan bagi para praktisi untuk bertanya dan menyampaikan pertanyaanpertanyaan pada saat serah terima,dan melibatkan para pasien serta keluarga dalam proses serah terima.

d. Pastikan Tindakan yang benar pada Sisi Tubuh yang benar.

Penyimpangan pada hal ini seharusnya sepenuhnya dapat dicegah. Kasus-kasus dengan pelaksanaan prosedur yang keliru atau pembedahan sisi tubuh yang salah sebagian besar adalah akibat dan miskomunikasi dan tidak adanya informasi atau informasinya tidak benar. Faktor 
yang paling banyak kontribusinya terhadap kesalahan-kesalahan macam ini adalah tidak ada atau kurangnya proses pra-bedah yang distandardisasi. Rekomendasinya adalah untuk mencegah jenis-jenis kekeliruan yang tergantung pada pelaksanaan proses verifikasi prapembedahan; pemberian tanda pada sisi yang akan dibedah oleh petugas yang akan melaksanakan prosedur; dan adanya tim yang terlibat dalam prosedur Time out sesaat sebelum memulai prosedur untuk mengkonfirmasikan identitas pasien, prosedur dan sisi yang akan dibedah.

e. Kendalikan Cairan Elektrolit Pekat (concentrated).

Sementara semua obat-obatan, biologics, vaksin dan media kontras memiliki profil risiko, cairan elektrolit pekat yang digunakan untuk injeksi khususnya adalah berbahaya. Rekomendasinya adalah membuat standardisasi dari dosis, unit ukuran dan istilah; dan pencegahan atas campur aduk/bingung tentang cairan elektrolit pekat yang spesifik.

f. Pastikan Akurasi Pemberian Obat pada Pengalihan Pelayanan.

Kesalahan medikasi terjadi paling sering pada saat transisi/pengalihan. Rekonsiliasi (penuntasan perbedaan) medikasi adalah suatu proses yang didesain untuk mencegah salah obat (medication errors) pada titik-titik transisi pasien. Rekomendasinya adalah menciptakan suatu daftar yang paling lengkap dan akurat dan seluruh medikasi yang sedang diterima pasien juga disebut sebagai "home medication list", sebagai perbandingan dengan daftar saat admisi, penyerahan dan/atau perintah pemulangan bilamana menuliskan perintah medikasi; dan komunikasikan daftar tsb kepada petugas layanan yang berikut dimana pasien akan ditransfer atau dilepaskan.

g. Hindari Salah Kateter dan Salah Sambung Slang (Tube).

Slang, kateter, dan spuit (syringe) yang digunakan harus didesain sedemikian rupa agar mencegah kemungkinan terjadinya KTD (Kejadian Tidak Diharapkan) yang bisa menyebabkan cedera atas pasien melalui penyambungan spuit dan slang yang salah, serta memberikan medikasi atau cairan melalui jalur yang keliru. Rekomendasinya adalah menganjurkan perlunya perhatian atas medikasi secara detail/rinci bila sedang mengenjakan pemberian medikasi serta pemberian makan (misalnya slang yang benar), dan bilamana menyambung alat-alat kepada pasien (misalnya menggunakan sambungan \& slang yang benar).

h. Gunakan Alat Injeksi Sekali Pakai. 
Salah satu keprihatinan global terbesar adalah penyebaran dan HIV, HBV, dan HCV yang diakibatkan oleh pakai ulang (reuse) dari jarum suntik. Rekomendasinya adalah penlunya melarang pakai ulang jarum di fasilitas layanan kesehatan; pelatihan periodik para petugas di lembaga-lembaga layanan kesehatan khususnya tentang prinsip-pninsip pengendalian infeksi,edukasi terhadap pasien dan keluarga mereka mengenai penularan infeksi melalui darah;dan praktek jarum sekali pakai yang aman.

i. Tingkatkan Kebersihan Tangan (Hand hygiene) untuk Pencegahan lnfeksi Nosokomial.

Diperkirakan bahwa pada setiap saat lebih dari 1,4 juta orang di seluruh dunia menderita infeksi yang diperoleh di rumah-rumah sakit. Kebersihan Tangan yang efektif adalah ukuran preventif yang pimer untuk menghindarkan masalah ini. Rekomendasinya adalah mendorong implementasi penggunaan cairan "alcohol-based hand-rubs" tersedia pada titiktitik pelayan tersedianya sumber air pada semua kran, pendidikan staf mengenai teknik kebarsihan taangan yang benar mengingatkan penggunaan tangan bersih ditempat kerja; dan pengukuran kepatuhan penerapan kebersihan tangan melalui pemantauan/observasi dan tehniktehnik yang lain.

\section{PENUTUP}

Budaya Keselamatan pasien merupakan hal yang mendasar di dalam pelaksanaan keselamatan di rumah sakit. Rumah sakit harus menjamin penerapan keselamatan pasien pada pelayanan kesehatan yang diberikannya kepada pasien (Fleming \& Wentzel, 2008). Upaya dalam pelaksanaan keselamatan pasien diawali dengan penerapan budaya keselamatan pasien (KKP-RS, 2008). Hal tersebut dikarenakan berfokus pada budaya keselamatan akan menghasilkan penerapan keselamatan pasien yang lebih baik dibandingkan hanya berfokus pada program keselamatan pasien saja (El-Jardali, Dimassi, Jamal, Jaafar, \& Hemadeh, 2011). Keselamatan (safety) telah menjadi isu global termasuk juga untuk rumah sakit. Oleh karena itu, keselamatan pasien merupakan prioritas utama untuk dilaksanakan dan hal tersebut terkait dengan terjadinya Insiden Keselamatan Pasien (IKP) di rumah sakit. Penerapan budaya keselamatan pasien yang adekuat akan menghasilkan pelayanan keperawatan yang bermutu. Pelayanan kesehatan yang bermutu tidak cukup dinilai dari kelengkapan teknologi, sarana prasarana yang canggih dan petugas kesehatan yang profesional, namun juga ditinjau dari proses dan hasil pelayanan yang diberikan (Ilyas, 2004). Outcome yang baik dapat tercapai jika terjadi peningkatan budaya keselamatan pasien di lingkungan rumah sakit. Peningkatan tersebut harus dipantau dan dapat diukur. 


\section{DAFTAR PUSTAKA}

Herawati, Y. T. (2015). BUDAYA KESELAMATAN PASIEN DI RUANG RAWAT INAP RUMAH SAKIT X KABUPATEN JEMBER. Jurnal IKESMA Volume, 11 (1)

Iriviranty, A. (2015). Analisis Budaya Organisasi dan Budaya Keselamatan Pasien Sebagai Langkah Pengembangan Keselamatan Pasien di RSIA Budi Kemuliaan Tahun 2014. Jurnal ARSI, 1 (3)

Mandriani, E., Hardisman., and Yetti, H. (2019). Analisis Dimensi Budaya Keselamatan Pasien Oleh Petugas Kesehatan di RSUD dr Rasidin Padang Tahun 2018. Jurnal Kesehatan Andalas, 8 (1)

Mudayana, A, A. (2014). PERAN ASPEK ETIKA TENAGA MEDIS DALAM PENERAPAN BUDAYA KESELAMATAN PASIEN DI RUMAH SAKIT. Supplemen Majalah Kedokteran Andalas, 37(1)

Najihah. (2018). Budaya Keselamatan Pasien Dan Insiden Keselamatan Pasien Di Rumah Sakit: Literature Review. Journal Of Islamic, 3 (1)

Pagala, I., Shaluhiyah, Z., \& Widjasena, B. (2017). Perilaku Kepatuhan Perawat Melaksanakan SOP Terhadap Kejadian Keselamatan Pasien di Rumah Sakit X Kendari. Jurnal Promosi Kesehatan Indonesia, 12(1), 138-141.

Permenkes No. 11. (2017). Tentang Keselamatan Pasien

Simamora, R. H. (2018). Buku ajar keselamatan pasien melalui timbang terima pasien berbasis komunikasi efektif: SBAR. Medan: USUpress.

Simamora, R. H. (2020). Learning of Patient Identification in Patient Safety Programs Through Clinical Preceptor Models. Medico Legal Update, 20(3), 553-556.

Tutiani., Lindawati and Krisanti P. (2017). Bahan Ajar Keperawatan: MANAJEMEN KESELAMATAN PASIEN. Jakarta Selatan: Pusdik SDM Kesehatan (KemenKes RI)

Yasmi, Y \& Thabrany, H. (2018). Faktor-Faktor yang Berhubungan dengan Budaya Keselamatan Pasien di Rumah Sakit Karya Bhakti Pratiwi Bogor Tahun 2015. Jurnal ARSI, 4 (2)

Yeni, Y., \& Maswarni. (2019). Budaya Keselamatan Pasien Pada Perawat Di Instalasi Perawatan Intensive Rsud Arifin Achmad Provinsi Riau. Jurnal Keperawatan Priority, 2 (2) 